\title{
USE OF FUZZY MATHEMATICAL QUADRATIC PROGRAMMING APPROACH IN JOB EVALUATION
}

Manoj Kumar Mandal ${ }^{*}$, Arun Prasad Burnwal ${ }^{2}$, Neelam Dubey ${ }^{3}$, Om Prakash Dubey ${ }^{4}$

${ }^{1 *}$ Pemiya Rishikesh Institute of Technology, Dhanbad, Jharkhand, India; ${ }^{2}$ Department of Mathematics, GGSESTC, Bokaro, Jharkhand, India; ${ }^{3}$ Department of Mathematics, Veer Kunwar Singh University, Ara, Bhojpur, Bihar, India;

${ }^{4}$ Department of Mathematics, J. J. College, Veer Kunwar Singh University, Ara, Bhojpur, Bihar, India. Email: ${ }^{*}$ mkmandal346@gmail.com, ${ }^{2}$ apburnwal@yahoo.com, ${ }^{3}$ neelamdubey03@gmail.com,

${ }^{4}$ omprakashdubeymaths@gmail.com

Article History: Received on $12^{\text {th }}$ April 2021, Revised on $30^{\text {th }}$ April 2021, Published on $15^{\text {th }}$ May 2021

\begin{abstract}
Purpose of study: The current paper is the based on mathematical model of the job evolution system.

Methodology: The proposed method is the fusion of quadratic programming and fuzzy logic where quadratic programming is used to optimize objective function with related constraints in the form of non-linear formulation. Fuzzy logic is used to control uncertainty related information by estimating imprecise parameters
\end{abstract}

Main Finding: The optimal solution of the job evaluation based on fuzzy environment where goal is imprecise.

Application of this study: It is used in the areas where information is not exact.

The originality of this study: The novelty of the method is the fusion of quadratic programming and fuzzy logic.

Keywords: Job Evolution, Quadratic Programming, Fuzzy Logic, Achievement Function, Imprecise Information.

\section{INTRODUCTION}

Modeling in Job Evaluation is the important tool that facilitates the solution of non-bench mark jobs by reference to the evaluation of benchmark job It is the systematic process to determine the worth of one job in relation to other jobs in any orgation an enterprise. It is required to arc the relation worth of many jobs be paid depending upon the worth of the job. It focuses is typically on the duties and responsibilities assigned to a job, not on the credentials or charters tic the jobrelated person nor the quality or quantity of the incumbent's performance.

Employment Assessment Goals The following are some examples:

1 To obtain and retain a complete, correct, and impersonal description of each specific job or occupation in the factory.

2 To provide a consistent method for calculating the relative worth or importance of each job in a factory.

3 Establish a just and equal rate of pay for each job in comparison to other jobs in the factory, society, and industry.

4 To ensure that all eligible employees on similar jobs are paying the same salary.

5 Allow workers to be eligible for promotion and relocation fairly and correctly.

6 To provide a factual basis for comparing pay prices for related occupations both Geographically and Nationally.

The following are the requirements:

(a) Determining the work system and architecture.

(b) Making it possible for recognized trade unions to join.

(c) Ensuring that market analysis is conducted successfully prior to work review.

(d) Ensuring that all parties, labor, workers, and management are included on the committee.

(e) Encouraging constructive participation in the assessment process.

(f) Making it possible to recruit outside consultants to contribute experience to the process.

(g) Material on task research is readily available.

(h) The task appraisal framework should be treated as a collective bargaining modification.

(i) The active participation of a labor union and employers is important.

(j) Access to business prices (via a Labour sector survey) in order to determine current wage prices.

(k) Determining which classes of workers and jobs will be evaluated by the scheme.

Job evaluation helps in developing and maintaining pay structures by comparing the relative similarities and differences in the content and the value of jobs. If in an organization the pay structure is illogical then the pay inequalities may exist. 
The purpose of job evolution is to eliminate the pay inequalities Leep, T. L. and Michael D. Crino (1990) and Milkovich, G.T. and Boudreau, W. (1990).

In this paper, an attempt has been made to solve the job evaluation problem using the fuzzy goal programming approach. Since practically it is difficult for the decision-maker to fix the goals absolutely for the benchmark jobs. So, it is considered that the scoring goals as fuzzy in nature. The concept of fuzzy set developed by Bellman, R.E. and Zadeh, L.A.(1970) and Zimmermann, H.J. (1978) has been utilized to tackle the problem. Fuzzy logic is a part of soft computing (Das, S. K., Kumar, A., Das, B., \& Burnwal, A. P. (2013)) which is rapidly used in a wireless network as well as wireless sensor network to solve several problems Das, S. K., Samanta, S., Dey, N., \& Kumar, R. (2020), De, D., Mukherjee, A., Das, S. K., \& Dey, N. (2020). There are several works are proposed by different authors Das, S. K., Tripathi, S., \& Burnwal, A. P. (2015a), Das, S. K., Tripathi, S., \& Burnwal, A. P. (2015b), Das, S. K., Tripathi, S., \& Burnwal, A. P. (2015c), Das, S. K., \& Tripathi, S. (2020), Tiwari, R., Dharmar, S., Rao, J. (1987), Hannanm, E. L. (1981), Mukherjee, Burnwal, A.P. and Singh, D. (2000), Bing -Yuan, C. (1993), Ammar, E. (2009) and Chakraborty, M., Dubey, O. P.(2001) to illustrates the achievement of the fuzzy logic. In the proposed approach the worth's of the different factor levels of each factor which are components of the benchmark job may be computed. With these computed worth's of various factor levels, it will be possible to compute the scores for different types of jobs and thus jobs may be evaluated. A sample problem has been solved using the proposed approach.

\section{MODEL ANALYSIS}

Let $x_{i}$ is a job factor. It has a finite number of levels $x_{i j}$, $i \in[1, n]$. The management of the organization identifies $K$ benchmark jobs $\mathrm{y}_{\mathrm{n}}(\mathrm{x}), \mathrm{n} \in[1, \mathrm{~K}]$ whose levels and scopes

$\left(\mathrm{s}_{\mathrm{n}}, \mathrm{n} \in[1, \mathrm{~K}]\right)$ are known. Similarly, the score constraints for the lowest levels for each factor are known, and also the differences of scores of each level of a factor from the previous levels are also known. These constraints have been considered as rigid constraints.

Fuzzy mathematical model for the above-mentioned job evolution problem may be developed as:

\section{MATHEMATICAL MODEL}

Determine an action $\mathrm{x}=\left(\mathrm{x}_{11, \ldots \ldots . . .} \mathrm{x}_{1 \mathrm{~m}}\right.$;

$$
\begin{aligned}
& \mathrm{X}_{21 \ldots \ldots \ldots . . .} \mathrm{X}_{2 \mathrm{~m}} ; \\
& \left.\mathrm{X}_{\mathrm{m} 1 \ldots \ldots . . .} \mathrm{X}_{\mathrm{mn}}\right)
\end{aligned}
$$

Such that

$$
\begin{aligned}
& y_{i}(x) \bar{\equiv}_{s_{n}} \\
& x_{i m} \leq U_{i} \\
& x_{i j} \geq L_{i} \\
& x_{i j}-x_{i j-1} \geq D_{i} \\
& x_{i j} \geq 0
\end{aligned}
$$

where ' $\sim$ ' sign denotes fuzziness. For defuzzification, linear membership function is used as:

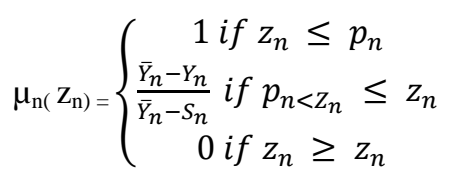

$$
\begin{aligned}
& \mu_{\mathrm{n}}^{\prime}\left(Z_{\mathrm{n}}\right)= \begin{cases}1 & \text { if } Y_{n} \geq S_{n} \\
\frac{\bar{Y}_{n}-Y_{n}}{\bar{Y}_{n}-S_{n}} & \text { if } p_{n}<Y_{n} \leq Y_{n} \\
0 & \text { if } Y_{n} \leq S_{n}\end{cases}
\end{aligned}
$$

where, $\bar{y}$ and $y$ are the maximum and minimum values of $\mathrm{y}_{\mathrm{n}}(\mathrm{x})$. The first membership function is non decreasing function whereas the second membership function is non increasing function. The membership function for Fuzzy inequality greater or equivalent may be obtained.

Using nonlinear operator (quadratic) $\mu$ the Fuzzy model reduces to crisp model as:

$$
\begin{array}{ll}
\operatorname{Max} \Sigma \mu_{n}^{2}+\mu_{n}^{2} & \\
\text { Subject to } & y_{n}+\left(\bar{y}_{n}-s_{n}\right) \mu_{n} \leq \bar{y} t, \\
& y_{n}-\left(s_{n}-y_{t}\right) \mu \leq y_{t}
\end{array}
$$




$$
\begin{aligned}
& X_{i n}+\left(\bar{U}_{i}-U_{i}\right) \leq \bar{U}_{i} ; x_{i j} \geq L_{i} \\
& x_{i j}-x_{i j-1} \geq D_{i}(j=2,3, \ldots, n) \\
& x_{i j} \geq 0,
\end{aligned}
$$

where $\bar{U}_{i}$ are the tolerable limits for the highest levels of the factors and $i=1,2,3, \ldots \ldots \mathrm{m}$; $\mathrm{j}=1,2,3, \ldots, \mathrm{n} ; \mathrm{t}=1,2,3, \ldots, \mathrm{k}$. model (3) may be solved using Lingo software technique.

\section{NUMERICAL PROBLEM}

The management of the organization has four factors each job with six levels of each factor and identified five benchmarks' jobs with fuzzy worth's

Mathematical analysis

$$
\begin{aligned}
& \mathrm{x}_{16}+\mathrm{x}_{26}+\mathrm{x}_{36}+\mathrm{x}_{46} \bar{\Xi}_{125} \\
& \mathrm{x}_{15}+\mathrm{x}_{25}+\mathrm{x}_{35}+\mathrm{x}_{45} \text { 戸 } 100 \\
& \mathrm{x}_{14}+\mathrm{x}_{24}+\mathrm{x}_{34}+\mathrm{x}_{44} \equiv 90 \\
& \mathrm{x}_{13}+\mathrm{x}_{23}+\mathrm{x}_{33}+\mathrm{x}_{43} \bar{\Xi}_{70} \\
& \mathrm{x}_{12}+\mathrm{x}_{22}+\mathrm{x}_{32}+\mathrm{x}_{42} \equiv 6 \\
& \mathrm{x}_{11} \geq 0 \\
& \mathrm{x}_{22} \geq 0 \\
& \mathrm{x}_{\mathrm{ij}}-\mathrm{X}_{\mathrm{ij}-1} \geq_{2} \\
& \mathrm{x}_{\mathrm{ij}} \geq 0
\end{aligned}
$$

Where the first benchmark job represents the top labor grade job in that organization. The fuzzy worth's of the highest levels of each factor (with a limit of tolerance) the know scores for lower levels of each factor and the known amount by which by which a particular level is higher than the preceding level are decided as.

Now with the proposed methodology the crisp form for the above fuzzy model is obtained as

$\operatorname{Max}$

$$
\sum_{i=1}^{j} \mu_{i}^{2}+\sum_{i=1}^{j} \mu_{i}^{\prime 2}
$$

Such that

$$
\begin{aligned}
& \mathrm{x}_{16}+\mathrm{x}_{26}+\mathrm{x}_{36}+\mathrm{x}_{46}+25 \mu_{1} \leq 150 \\
& \mathrm{x}_{15}+\mathrm{x}_{25}+\mathrm{x}_{35}+\mathrm{x}_{45}+30 \mu_{2} \leq 130 \\
& \mathrm{x}_{14}+\mathrm{x}_{24}+\mathrm{x}_{34}+\mathrm{x}_{44}+35 \mu_{3} \leq 125 \\
& \mathrm{x}_{13}+\mathrm{x}_{23}+\mathrm{x}_{33}+\mathrm{x}_{43}+50 \mu_{4} \leq 120 \\
& \mathrm{x}_{11}+\mathrm{x}_{22}+\mathrm{x}_{32}+\mathrm{x}_{42}+40 \mu_{5} \leq 110 \\
& \mathrm{x}_{16}+\mathrm{x}_{26}+\mathrm{x}_{36}+\mathrm{x}_{46}-45 \mu^{\prime}{ }_{1} \geq 60 \\
& \mathrm{x}_{15}+\mathrm{x}_{25}+\mathrm{x}_{35}+\mathrm{x}_{45}-35 \mu^{\prime}{ }_{2} \geq 55 \\
& \mathrm{x}_{14}+\mathrm{x}_{24}+\mathrm{x}_{34}+\mathrm{x}_{44}-30 \mu{ }_{3} \geq 40 \\
& \mathrm{x}_{13}+\mathrm{x}_{23}+\mathrm{x}_{33}+\mathrm{x}_{43}-25 \mu{ }_{4} \geq 30 \\
& \mathrm{x}_{11}+\mathrm{x}_{22}+\mathrm{x}_{32}+\mathrm{x}_{42}-25 \mu{ }_{5} \geq 35 \\
& \mathrm{x}_{16}+5 \mu{ }_{6}{ }_{6} \leq 25 \\
& \mathrm{x}_{\mathrm{ij}} \geq 0 \\
& (\mathrm{i}=1,2,3, \ldots . .4 ; \mathrm{j}=1,2,3, \ldots \ldots \ldots . .5)
\end{aligned}
$$$$
\mathrm{X}_{\mathrm{ij}}-\mathrm{X}_{\mathrm{ij}-1} \geq_{2}
$$ 
$(i=1,2,3,4 ; j=1,2,3,4,5,6)$

On the solving (QP) using Lingo Software, the following numerical values worth of various factor at different levels are obtained as:

Table 1: Worth of compensation factors

\begin{tabular}{lllllll}
\hline Level factor & $\mathbf{1}$ & $\mathbf{2}$ & $\mathbf{3}$ & $\mathbf{4}$ & $\mathbf{5}$ & $\mathbf{6}$ \\
\hline $\mathrm{X} 1$ & 0.00000 & 0.00000 & 0.00000 & 0.00000 & 0.00000 & 0.00000 \\
\hline $\mathrm{X} 2$ & 0.00000 & 0.00000 & 27.53086 & 0.00000 & 0.00000 & 0.00000 \\
\hline $\mathrm{X} 3$ & 0.00000 & 0.00000 & 1.23456 & 38.76543 & 0.00000 & 0.00000 \\
\hline $\mathrm{X} 4$ & 0.00000 & 33.76543 & 1.23456 & 1.23456 & 95.38462 & 58.76543 \\
\hline
\end{tabular}

Hence, the benchmark jobs are computed and tabulated as given below

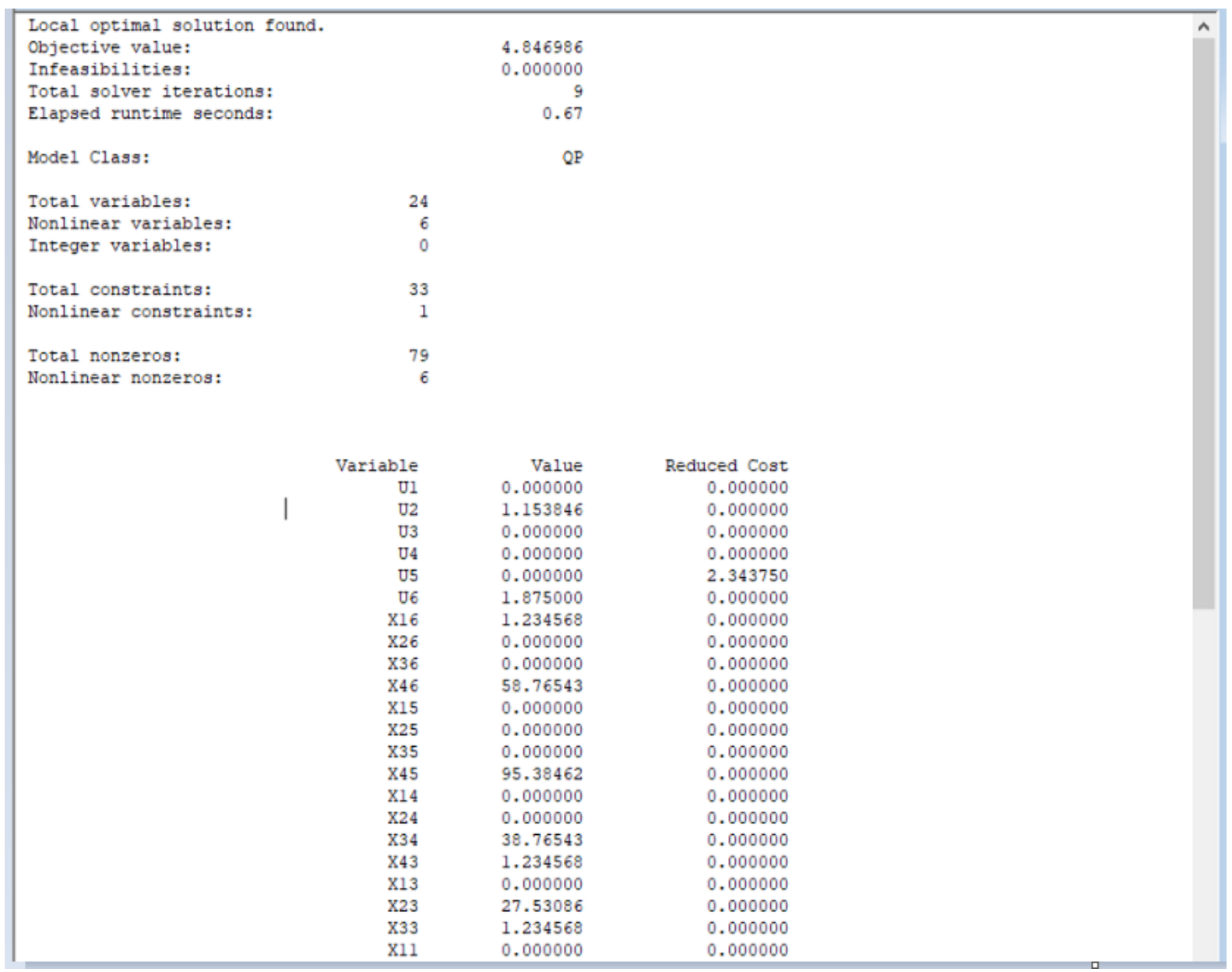

Figure 1: Benchmark jobs are computed and tabulated

Table 2: Scores of the benchmark jobs

\begin{tabular}{ll}
\hline Benchmark jobs & Scores \\
\hline 1 & 95.38462 \\
\hline 2 & 58.76543 \\
\hline 3 & 39.9999 \\
\hline 4 & 33.76543 \\
\hline 5 & 29.99995 \\
\hline
\end{tabular}

Table 3: Simulation parameters

\begin{tabular}{ll}
\hline Parameter & Description \\
\hline Software & LINGO \\
\hline Non-linear variable & 6 \\
\hline
\end{tabular}




\begin{tabular}{ll}
\hline Constraints & 33 \\
\hline Optimization & Maximum and Minimum \\
\hline Nature of objectives & Non-Linear \\
\hline Membership function & Two $\left(\mu\right.$ and $\left.\mu^{\prime}\right)$ \\
\hline Number of variables & 24 \\
\hline Model Name & Job factor \\
\hline Total Solver value & 9 \\
\hline Nature of Constraints & Linear \\
\hline
\end{tabular}

\section{CONCLUSION}

The values of the variables at various levels and the ratings of the various benchmark workers can be determined using tables 2 above. Table 1 demonstrates how to measure the score of every job made up of different levels of various variables. Management will also determine any work depending on a number of criteria. Assume that the highest labor grade benchmark job's base cost per hour is established, and that management needs to test a position with varying degrees of multiple variables. The new job's base rate will then be determined as follows:

Score of new job X $\frac{\text { Base rate of top Laboure grade benchmark job }}{\text { Scope of the Laboure grade benchmark job }}$

The min operator has been maximized in this prepossessed model in order to simplify the decision. The optimum value of is found to be $=4.846986$, resulting in the best work appraisal judgment.

\section{REFERENCES}

1 Ammar, E. (2009). On fuzzy random multi objective quadratic programming. European Journal of Operational Research, 193(2), 329-341. https://doi.org/10.1016/j.ejor.2007.11.031

2 Bellman, R.E. and Zadeh, L.A.(1970). Management Science, ser. B. 17, $141-164$. https://doi.org/10.1287/mnsc.17.4.B141

3 Bing -Yuan, C. (1993). Fuzzy Quadratic programming. Fuzzy sets and Systems, 53, 135 - 153. https://doi.org/10.1016/0165-0114(93)90168-H

4 Chakraborty, M., Dubey, O. P.(2001). Goal Programming with Quadratic Preferences - An iterative Approach. International Journal of Management and System, 17(01), 25-34.

5 Das, S. K., \& Tripathi, S. (2020). A Nonlinear Strategy Management Approach in Software-Defined Ad hoc Network. Design Frameworks for Wireless Networks, 321-346. Springer, Singapore. https://doi.org/10.1007/978-981-13-9574-1_14

6 Das, S. K., Kumar, A., Das, B., \& Burnwal, A. P. (2013). On soft computing techniques in various areas. Computer Science \& Information Technology (CS \& IT), 3, 59-68. https://doi.org/10.5121/csit.2013.3206

7 Das, S. K., Samanta, S., Dey, N., \& Kumar, R. (2020). Design frameworks for wireless networks. Springer, Singapore. https://doi.org/10.1007/978-981-13-9574-1

8 Das, S. K., Tripathi, S., \& Burnwal, A. P. (2015a). Fuzzy based energy efficient multicast routing for ad-hoc network. In Proceedings of the 2015 Third International Conference on Computer, Communication, Control and Information Technology (C3IT), pp. 1-5. IEEE. https://doi.org/10.1109/C3IT.2015.7060126

9 Das, S. K., Tripathi, S., \& Burnwal, A. P. (2015b). Intelligent energy competency multipath routing in wanet. In Information systems design and intelligent applications, pp. 535-543. Springer, New Delhi. https://doi.org/10.1007/978-81-322-2250-7_53

10 Das, S. K., Tripathi, S., \& Burnwal, A. P. (2015c). Design of fuzzy based intelligent energy efficient routing protocol for wanet. In Proceedings of the 2015 Third International Conference on Computer, Communication, Control and Information Technology (C3IT), pp. 1-4. IEEE. https://doi.org/10.1109/C3IT.2015.7060201

11 De, D., Mukherjee, A., Das, S. K., \& Dey, N. (2020). Nature Inspired Computing for Wireless Sensor Networks. Springer. https://doi.org/10.1007/978-981-15-2125-6

12 Hannanm, E. L. (1981). Linear programming with multiple fuzzy goals. Fuzzy sets and systems, 6 (3), $235-248$. https://doi.org/10.1016/0165-0114(81)90002-6

13 Leep, T. L. and Michael D. Crino (1990). Personnel/ Human Resource Management, Macmillan, New York.

14 Milkovich, G.T. and Boudreau, W. (1990). John Personnel/ Human Resource Management (diagnostic approach), $5^{\text {th }}$ ed.

15 Mukherjee, Burnwal, A.P. and Singh, D. (2000). Fuzzy Geometric Programming using additive operative, News bull. Cal. Math. Society 23 (5\&6), P.20-24.

16 Tiwari, R., Dharmar, S., Rao, J. (1987). Fuzzy goal programming an additive model. Fuzzy sets and systems, 24(1), 27-34. https://doi.org/10.1016/0165-0114(87)90111-4

17 Zimmermann, H.J. (1978). Fuzzy programming and linear programming with general objective functions. Fuzzy sets and systems, 1, pp.45. https://doi.org/10.1016/0165-0114(78)90031-3 